\title{
Light and Electron-Microscopic Studies on the Tubal Tonsil of the Buffalo (Bubalus bubalis)
}

\author{
Ibrahim Alhaji Girgiri and Pawan Kumar
}

\author{
Department of Veterinary Anatomy, College of Veterinary Sciences, Lala Lajpat Rai University of Veterinary \\ and Animal Sciences, Hisar-125 004, India
}

\begin{abstract}
The tubal tonsils of 12 adult buffaloes of the local mixed breed were studied using light and electron microscopy. The tonsillar mucosa lined by pseudostratified columnar ciliated epithelium with goblet cells was modified into lymphoepithelial, due to its association with underlying lymphoid tissue. The lymphoepithelial further modified into follicle-associated epithelium (FAE) characterised by absence of the ciliated cells, goblet cells and the presence of more lymphocytes. The FAE exhibited varying modifications and presented M-cells intimately associated with lymphocytes. At places, the change of the epithelium also showed the presence of specialised M-cell like cells without any association with lymphoid tissue. The lymphoid tissue was in the form of isolated lymphocytes, diffuse aggregations and follicles. The goblet cells of the respiratory epithelium and the glandular acinar cells showed positive activity for the different carbohydrate moieties like acidic and neutral mucopolysaccharides, glycogen, mucins, weakly sulfated acidic mucosubstances, hyaluronic acid and sialomucins. Scanning electron microscopy of the mucosal surface presented a dense mat of cilia, and the FAE exhibited a heterogeneous population of microvillus and M-cells. Transmission electronmicroscopy demonstrated the different cell organelles of the various epithelia as well as the cellular profiles of the propria-submucosa, including the high endothelial venules where lymphocytes migration by both inter-endothelial and transvascular routes was also observed. The structural features of the tubal tonsil suggest that new strategies are required to explore this tonsil for targeted delivery of drugs and develop more effective vaccines by the intranasal route.
\end{abstract}

Keywords: Buffalo, Follicle-associated epithelium, Lymphoepithelium, M-cells, Tubal tonsil.

\section{INTRODUCTION}

The present study on light and electron-microscopic architecture of the tubal tonsil was envisaged with an emphasis on distribution of follicle-associated epithelium, M-cells, lymphoid tissue and high endothelial venules of buffaloes as compared with those of other domestic animals and humans. The tonsils are specialised lymphoepithelial structures situated at strategic anatomical areas of the oronasopharynx mucosa in a ring-like fashion called "von Waldeyer's-Hartz ring" [1]. The tonsils constitute part of the integrated mucosa-associated lymphoid tissue (MALT) which performs regional immune functions because of the exposure of their elements to both airborne and alimentary antigens [2]. This location plays a significant role in the tonsils as the first defence barrier, involved in antimicrobial immunity, immune exclusion, and oral tolerance [3]. Tonsils are typical secondary lymphoid organs which show similarities with lymph nodes but lack afferent lymphatics [4]. The lining of the tonsils presents an outward epithelium that is functionally modified to its surrounding tissues [5]. The mucosal crypts modified into specialised follicleassociated epithelium (FAE) [6] studded with M-cells [7] enabled sampling of exogenous antigens from the

*Address correspondence to this author at the Department of Veterinary Anatomy, College of Veterinary Sciences, Lala Lajpat Rai University of Veterinary and Animal Sciences, Hisar-125 004, India; Tel: +919466402637; E-mail: pkumar@luvas.edu.in; pawanrajoria2000@rediffmail.com mucosal surface to subepithelial lymphoid follicles [8] where appropriate clones of $T$ and $B$ cells can be selected and amplified prior to their migration into the surrounding mucosa [9]. The anatomical and ultrastructural characteristics of the tubal tonsil have been well described in the horse [10], and pigs [11]. A detailed study on the nasopharyngeal and lingual tonsils of the buffalo has been published recently [12, 13] however, lack of scientific literature on the tubal tonsil led to pursue the study in the buffaloes.

\section{MATERIALS AND METHODS}

\section{Histomorphology and Histochemistry}

The heads of 12 clinically healthy adult buffaloes (Bubalus bubalis) of 5-6 years of age of local mixed breed irrespective of sex were procured from Municipal Slaughter House Ghazipur, New Delhi, India immediately after their sacrifice by captive bolt stunning gun method. The tubal tonsils were collected and fixed in $10 \%$ neutral buffered formalin solution for 48 hours for histological studies. The fixed tissues were processed by routine paraffin technique, then sections of about 5-6 $\mu \mathrm{m}$ were cut and stained with Routine Harris' hematoxylin and eosin stain. Gomori's method used for reticulum tissues; Weigert's method for elastic fibres [14]; Crossman's trichrome stain for collagen fibres [15]; McManus' method for glycogen (PAS); Alcian blue method for mucosubstances ( $\mathrm{pH} 2.5)$; PASAlcian blue method for acidic and neutral 
mucosubstances ( $\mathrm{pH}$ 2.5); Meyer's mucicarmine method for mucin; a colloidal iron method for acid mucopolysaccharides [14]; and performic acid-Alcian blue method for proteins [16]. Permission from the Institutional Animal Ethical Committee was not required as the tissues were collected from slaughtered animals.

\section{Scanning Electron-Microscopy (SEM)}

Fresh tissues were collected at the slaughterhouse from 6 heads and fixed in $2 \%$ glutaraldehyde solution prepared in $0.1 \mathrm{M}$ phosphate buffer for $6-8$ hours at $4^{\circ} \mathrm{C}$, after thorough washing in chilled $0.1 \mathrm{M}$ phosphate buffer ( $\mathrm{pH}$ 7.4). The tissues were rewashed twice with $0.1 \mathrm{M}$ phosphate buffer, and the rest of the procedure was carried out at EM Lab., A.I.R.F., J.N.U.; A.I.I.M.S., New Delhi. The tissues were dehydrated using ascending grades of alcohol, critical point dried, mounted on stubs and sputter-coated with gold. The tissues were viewed using a scanning electron microscope (Zeiss EVO-40, New York, USA) at EM Labs., New Delhi.

\section{Transmission Electron-Microscopy (TEM)}

The tubal tonsillar tissues of approximately $1 \mathrm{~mm}$ thickness collected from the other six heads of buffaloes were primarily fixed in $2.5 \%$ glutaraldehyde solution prepared in $0.1 \mathrm{M}$ phosphate buffer for $6-8$ hours at $4^{\circ} \mathrm{C}$ and post-fixed in $2 \%$ osmium tetraoxide for 1 hour at $4^{\circ} \mathrm{C}$. The resin blocks were prepared, and thin sections of $1 \mu \mathrm{m}$ were stained with toluidine blue to select the most appropriate area of the tissue. The ultrathin sections (50-70 nm) were taken on copper grids, stained with uranyl acetate and lead citrate. The sections were viewed in a transmission electron microscope (Technai G2, SEl Co., Netherland) to record observations and areas of interest for photographs at EM Lab., AlIMS, New Delhi, India.

\section{RESULTS}

\section{Histomorphology and Histochemistry}

The tubal tonsillar surface was lined by a pseudostratified columnar ciliated epithelium with goblet cells (Figures 1-3). The free surface of the epithelium was undulating because of the folded mucosa. The epithelium was comprised of basal, ciliated columnar and the goblet cells. The oval nuclei of the basal cells were linearly arranged close to the basement membrane with their longitudinal axis perpendicular to the epithelium. Their chromatin material was condensed especially towards the outer nuclear membrane, thus, presenting a lighter stained central portion. The nuclei of the tall ciliated columnar cells were elongated, oval to rod shape and given chromatin material masking the appearance of nucleoli. The cytoplasm of these cell types was finely granular and eosinophilic. The goblet cells interspersed between rest of the cells, and their nuclei resembled those of the basal cells except that these were larger and the cytoplasm was vacuolated.

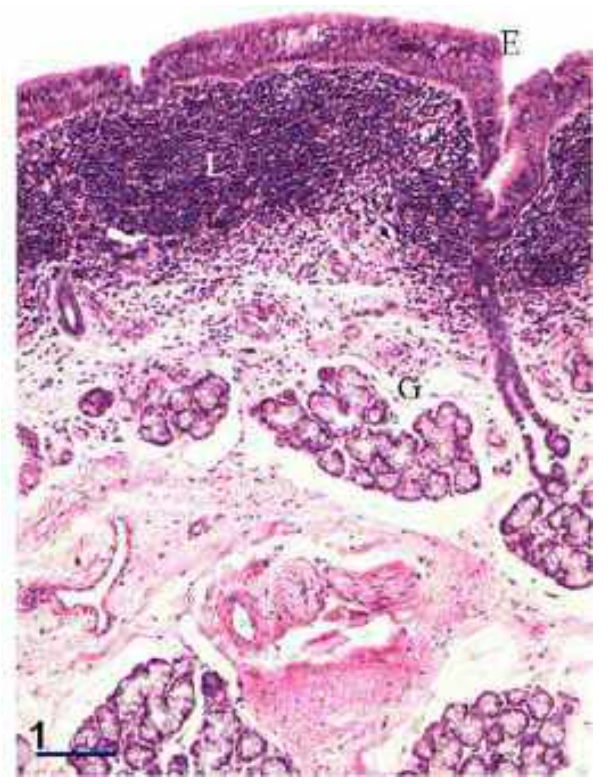

Figure 1: Photomicrograph of the tubal tonsil of buffalo showing respiratory epithelium $(E)$, lymphoid tissue $(L)$, and glandular tissue (G). H \& E x 40; (bar $450 \mu \mathrm{m}$ ).

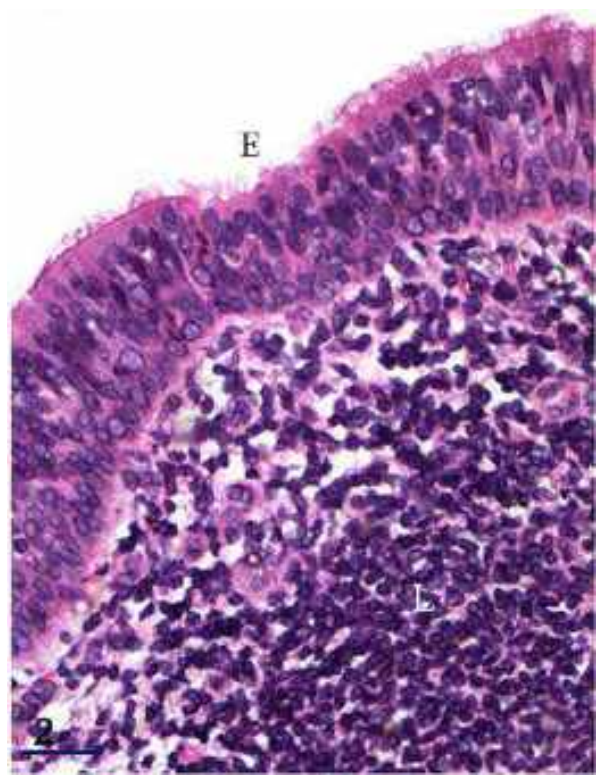

Figure 2: Photomicrograph of the tubal tonsil showing respiratory epithelium modified into follicle-associated epithelium (E), along with underlying lymphoid tissue $(L) . H$ \& E x 400; (bar $50 \mu \mathrm{m})$. 


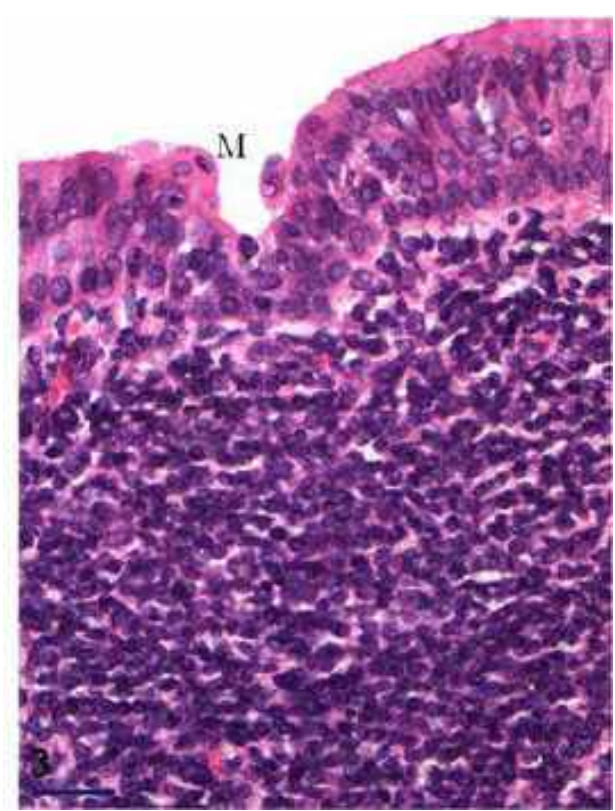

Figure 3: Photomicrograph of the tubal tonsil showing follicleassociated epithelium and the M-cells (M). H \& E x 400; (bar $50 \mu \mathrm{m})$

The free surface of the epithelium presented cilia of varying number and size (Figures 1 and 2). Lymphocytes infiltration was observed at different heights of the epithelium, especially towards the basal surface in the region where underlined lymphoid tissue was present. This epithelium was structurally designated as lymphoepithelial which was further modified into follicle-associated epithelium (FAE) or dome epithelium (Figures 2 and 3 ) due to association of underlying lymphoid follicle, and an absence of ciliated and the goblet cells. At places, the epithelium resembled stratified cuboidal, while at certain places the cell layers drastically reduced and it was difficult to discern the epithelial and the lymphoid cells. A few flat or dome-shaped cells of the area intimately associated with lymphocytes were designated as M-cells (Figure 3 ). These cells having round to oval, basophilic nuclei showed condensation of chromatin towards the periphery. The cytoplasm of these cells was finely granular and eosinophilic in nature. The FAE, including the M-cells, did not exhibit PAS-positive activity by any method employed for the present study.

The respiratory epithelium at some places further modified into simple to stratified cuboidal epithelium which was not having an association with the lymphoid follicle (Figure 4). Some of the surface epithelial cells were bulging having round to oval nuclei occupying the majority of the portion of the cell, thus giving the narrow rim of the cytoplasm a dome shape appearance. These special cells not associated with the lymphocytes were considered equivalent to the M-cells, and these were also devoid of PAS-positive activity.

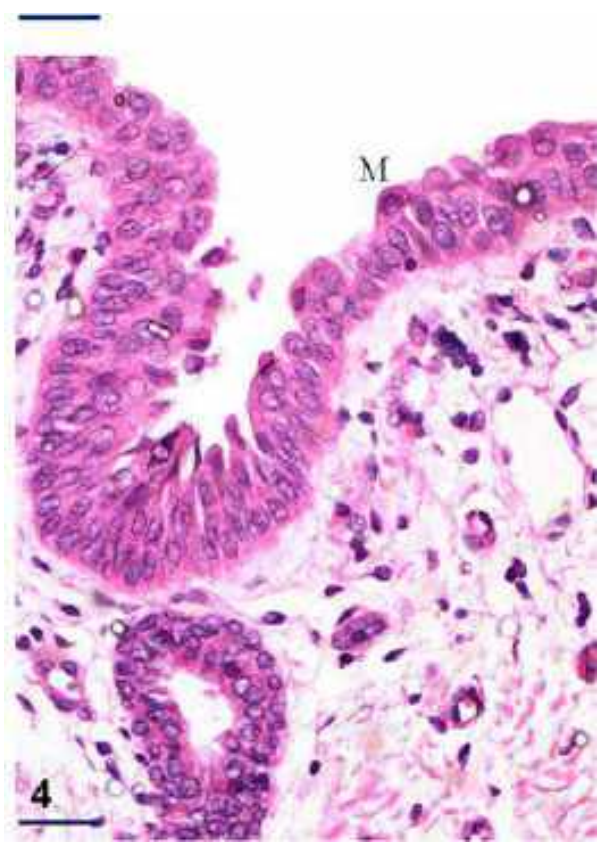

Figure 4: Photomicrograph of the tubal tonsil showing specialised epithelium not associated with lymphoid tissue but having M-like cells (M). H \& E x 400; (bar $50 \mu \mathrm{m}$ ).

The propria-submucosa was having loose irregular connective tissue and was mainly comprised of the different connective tissue fibres, lymphoid tissue, glandular tissue, blood vessels of varying shapes and dimensions, nerve bundles and fatty tissue. The tonsillar lymphoid tissue was mainly present in the form of isolated lymphocytes, diffuse aggregations and separate follicle-like structures. The isolated lymphocytes were mostly present in the subepithelial portion of the propria-submucosa, and a few infiltrated the epithelium. The diffusely scattered aggregations were irregularly present in the subepithelial part of the propria-submucosa. The lymphoid follicles were seen in the isolated pattern, and only 2-3 lymphoid follicles were present subsequently or adjacent to each other.

Generally, these follicles were comprised of lymphocytes of different size, and the adjacent follicles were separated from each other by the interfollicular areas which were occupied by the lymphocytes, a few plasma cells, macrophages, a few blood capillaries and a few high endothelial venules (HEVs). However, the corona and the germinal centres were occasionally observed in the present study. In the deepest part of propria-submucosa, the concentration of the elastic fibres was drastically increased in between the clusters of the glandular tissue and just ventral to the lymphoid 
tissue. The elastic fibres were also observed in the tunica intima of the blood vessels.

A stronger positive reaction was observed for acidic than neutral mucopolysaccharides (Figures $\mathbf{5}$ and $\mathbf{6}$ ) in the goblet cells. Alcianophilic positive reaction showed the presence of weakly sulfated acidic mucosubstances, hyaluronic acid and sialomucins (Figure 7). McManus' PAS method indicated the

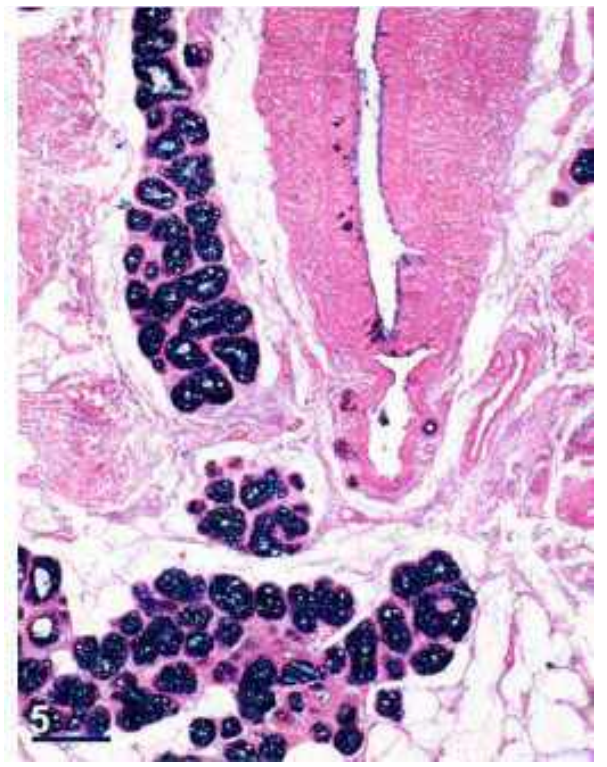

Figure 5: Photomicrograph of the tubal tonsil showing PAS positive goblet cells and glandular acini for acidic (blue color) and neutral (red color) mucopolysaccharides. PAS-AB x 100; (bar $200 \mu \mathrm{m}$ ).

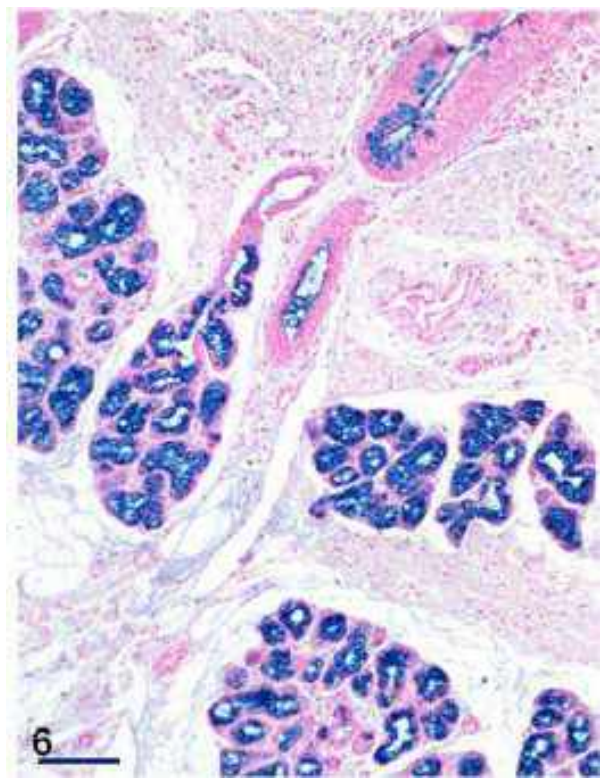

Figure 6: Photomicrograph of the tubal tonsil showing presence of acidic mucopolysaccharides in the epithelium and glandular tissue. Colloidal iron method x 100; (bar 200 $\mu \mathrm{m})$. presence of glycogen (Figure 8). The goblet cells showed positive reaction for colloidal iron, indicating the presence of acidic mucopolysaccharides, and mucins. The cysteine content was more than $4 \%$ as demonstrated by performic acid-AB technique. The PAS activity was lacking in rest of the portion of the epithelium.

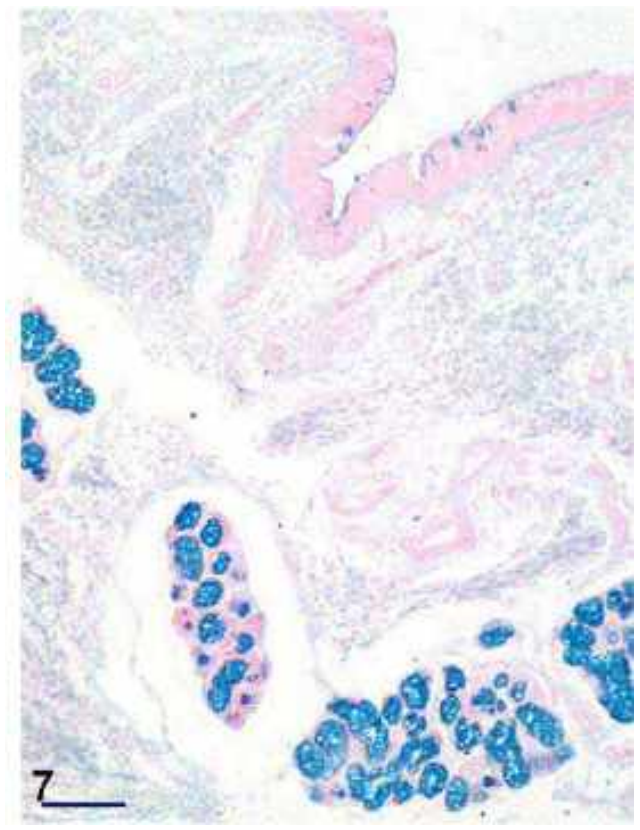

Figure 7: Photomicrograph of the tubal tonsil showing positive activity for weakly sulfated mucosubstances, sialomucins and hyaluronic acid in goblet cells of the epithelium and glandular acini. Alcian blue x 100; (bar 200 $\mu \mathrm{m})$.

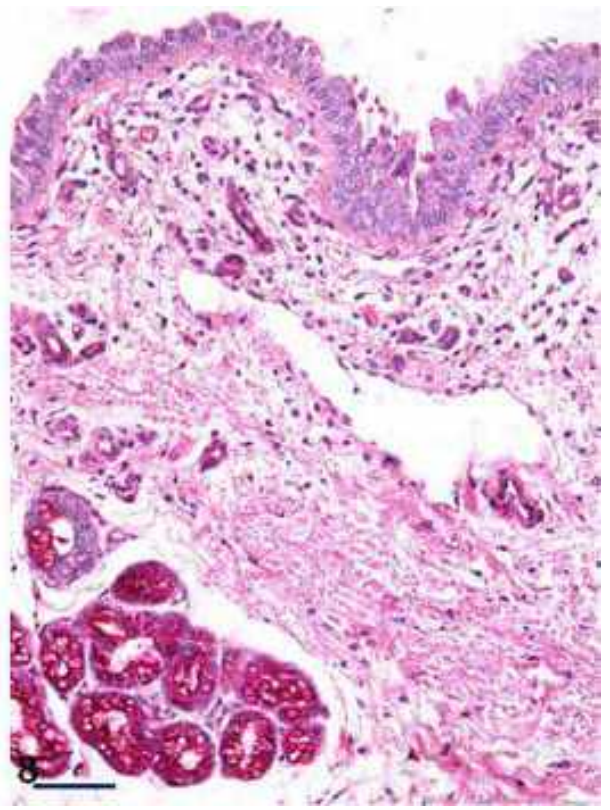

Figure 8: Photomicrograph of the tubal tonsil showing PAS positive reaction for glycogen in glandular acini and a few goblet cells. McManus' PAS method x 100; (bar $200 \mu \mathrm{m}$ ). 
The glandular acini showed a strong positive reaction for acidic and neutral mucopolysaccharides with the predominance of the former (Figures $\mathbf{5}$ and $\mathbf{6}$ ). The neutral mucopolysaccharides were very less and were present mainly towards the periphery of the glandular acini. The glandular acini, along with a few duct cells, presented Alcianophilic positive reaction showing the presence of weakly sulfated acidic mucosubstances, hyaluronic acid and sialomucins (Figure 7). These were also strongly positive for McManus' PAS (Figure 8) indicating the presence of glycogen. The cysteine content was more than $4 \%$ as demonstrated by performic acid-AB technique.

\section{SEM}

The scanning electron microscopy of the tubal tonsil presented a dense mat of ciliated cells (Figure 9). The

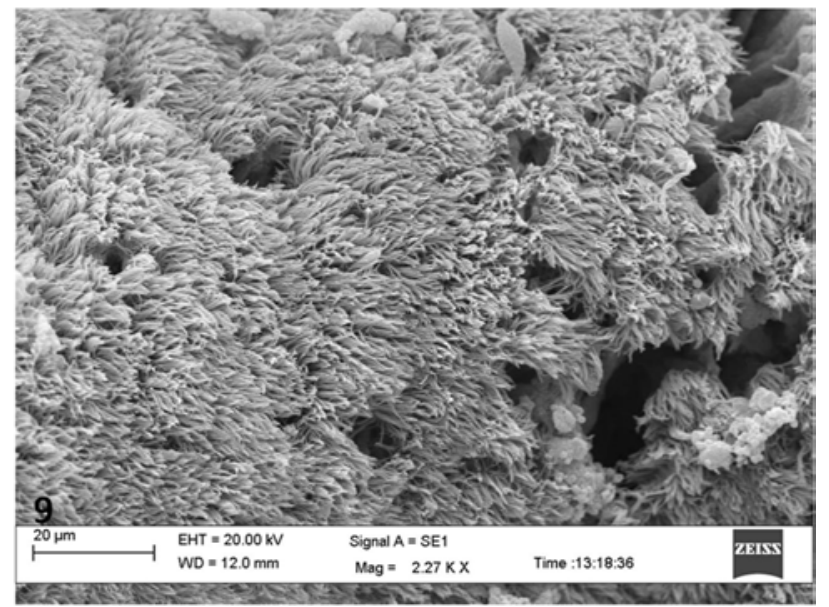

Figure 9: Scanning electron-micrograph of mucosal surface of the tubal tonsil of buffalo showing a dense mat of cilia and glandular ducts openings in between the clusters of the cilia. x 2270; (bar $20 \mu \mathrm{m})$.

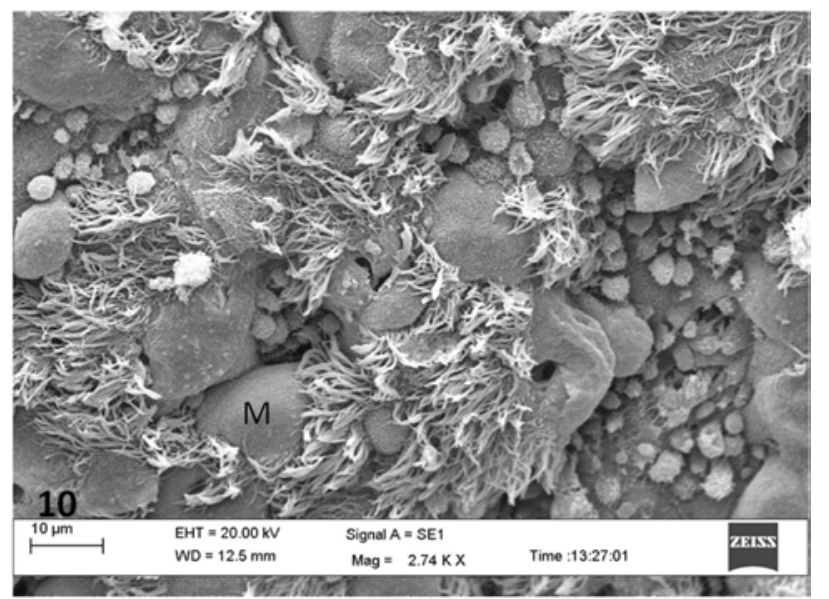

Figure 10: Scanning electron-micrograph of the tubal tonsil showing goblet and microvillus cells surrounded by ciliated cells and a few M-cells (M). x 2740; (bar $10 \mu \mathrm{m}$ ). tufts of the cilia were oriented in different directions, and their apical end presented blub-like structure. At some places, round openings observed in between the clusters of the cilia might be the opening of the underlying glandular ducts. Microvillus cells were only discernible, where the density of the ciliated cells was comparatively lesser. At some places, the microvillus cells were more dominant than the ciliated cells (Figures 10 and 11). A few microvillus cells were surrounded by a few ciliated cells, whereas other cells presented both microvilli as well as the cilia. A few microvillus cells possessed very small-sized microvilli which were considered as M-cells (Figure 12).

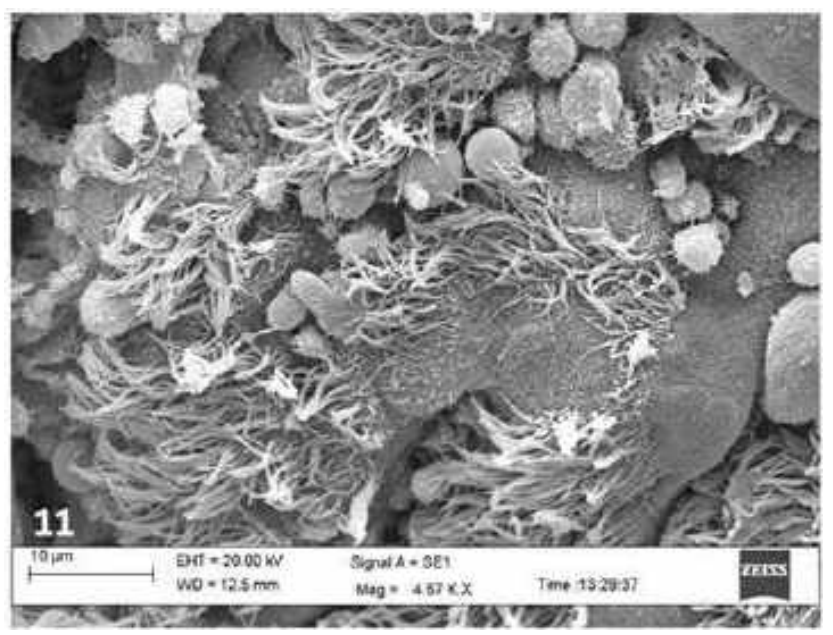

Figure 11: Scanning electron-micrograph of the tubal tonsil showing microvillus cells surrounded by ciliated and goblet cells. x 4570; (bar $10 \mu \mathrm{m})$.

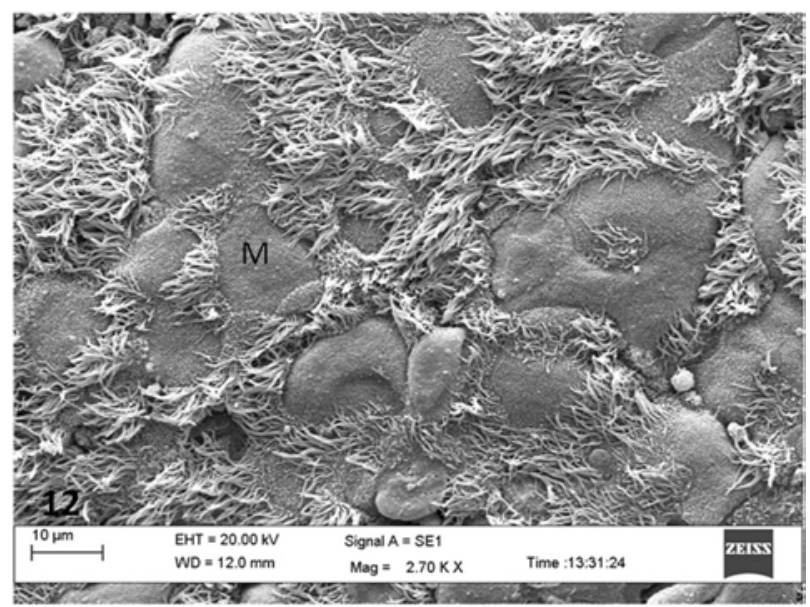

Figure 12: Scanning electron-micrograph of the tubal tonsil showing ciliated, M-cells (M) and a few cells having both microvilli and cilia. x 2700 (bar $10 \mu \mathrm{m}$ ).

\section{TEM}

The ultrastructural details of the columnar ciliated, basal and the goblet cells comprising the respiratory 
epithelial cells (Figures 13-16) confirmed those observed through light microscopy. The elongated nuclei of the columnar ciliated cells (Figure 13) were having small clumps of electron-dense chromatin material, whereas electron-plasm contained different cell organelles. The adjacent ciliated cells were attached by desmosomes, and their intercellular spaces presented interdigitating villi. The goblet cell had an electron-lucent nucleus with centric/eccentric nucleolus. These cells interspersed in between the ciliated and microvillus cells showed apical bleb or dome-shaped structures toward their free surface because of the presence of secretory granules (Figures 14 and 15). The microvillus cells were of different types and generally contained electron-lucent nuclei. Their electron-plasm had a higher number of mitochondria, and the free surface was having microvilli of varying shapes and size (Figure 16).

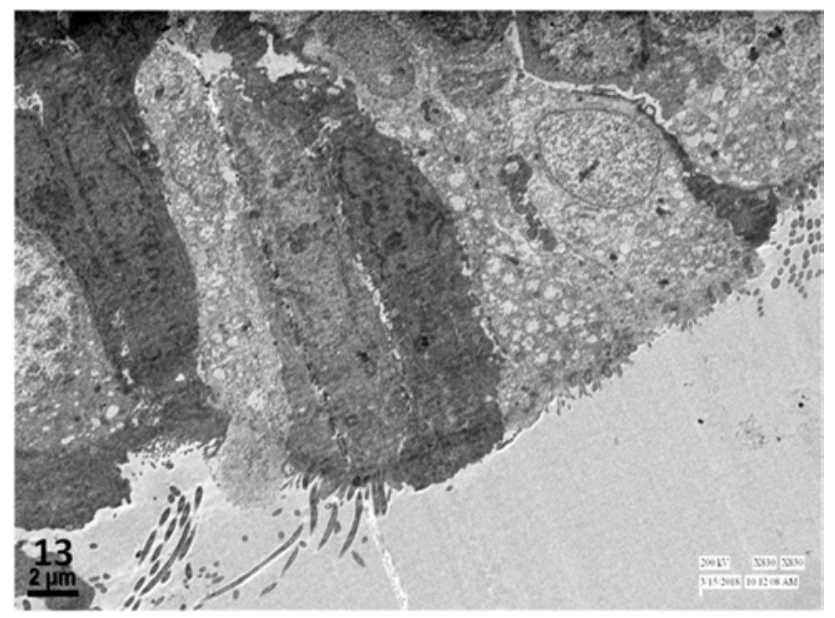

Figure 13: Transmission electron-micrograph of the tubal tonsil of the buffalo showing columnar ciliated, microvillus and the goblet cells. $x$ 830; (bar $2 \mu \mathrm{m})$.

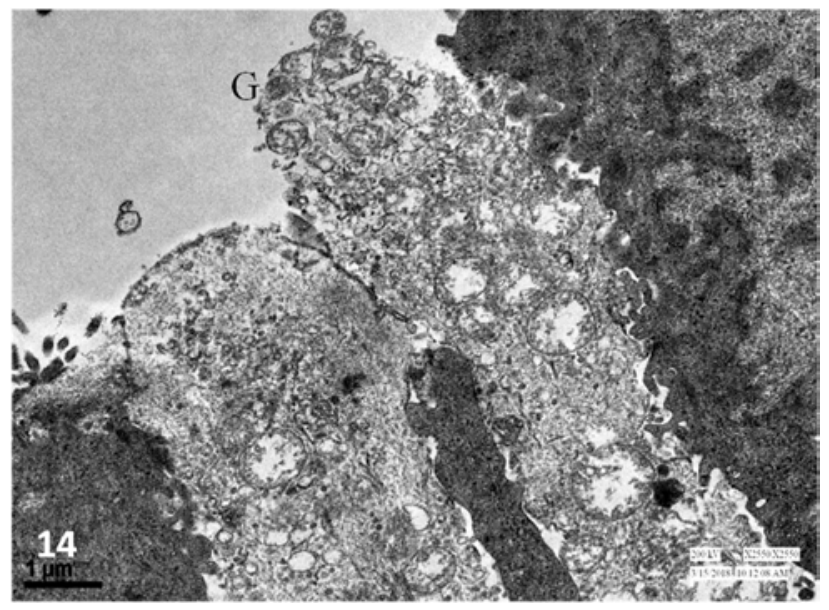

Figure 14: Transmission electron-micrograph of the tubal tonsil showing supranuclear portion of the goblet cell $(G) . x$ 2550; (bar $1 \mu \mathrm{m})$.

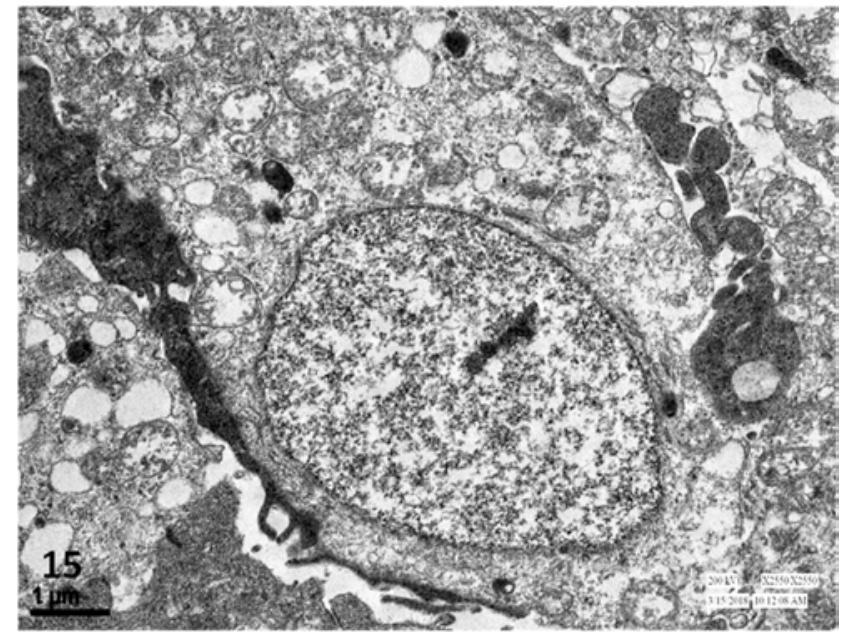

Figure 15: Transmission electron-micrograph of the tubal tonsil showing secretory droplet and basally placed electronlucent nucleus of the goblet cell. x 2550; (bar $1 \mu \mathrm{m}$ ).

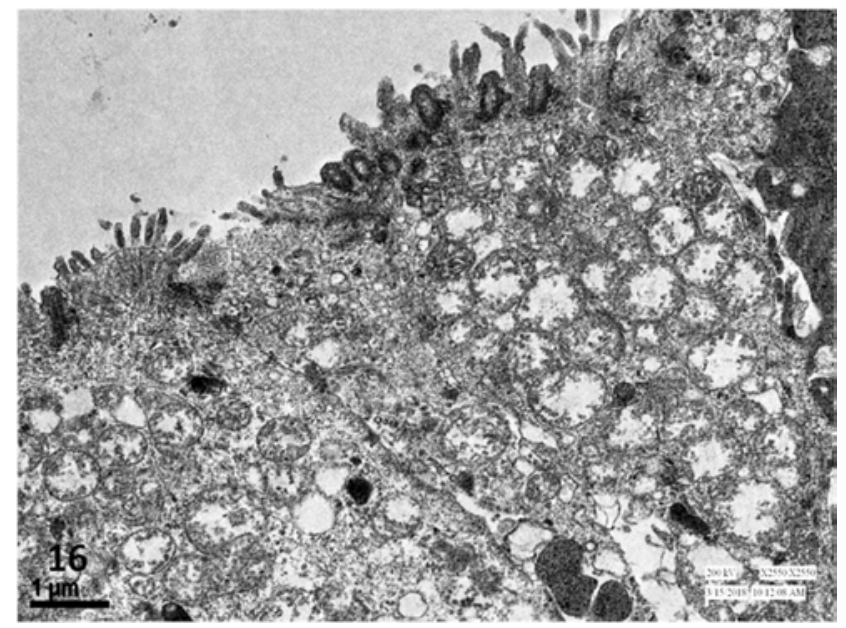

Figure 16: Transmission electron-micrograph of the tubal tonsil showing supranuclear portion of microvillus cell having small sized microvilli and large number of mitochondria. $x$ 2550; (bar $1 \mu \mathrm{m})$.

The follicle-associated epithelium had different types of microvillus cells (Mv) (Figures 17 and 18). The large-sized Mv cells were electron-dense. In addition, moderate electron-dense Mv cells were observed during the present study. These Mv cells presented the different cell organelles, especially mitochondria, Golgi bodies, smooth and rough endoplasmic reticulum, a few lysosomes like structure, a few secretory granules like structures. M-cells equivalent was observed in between these Mv cells (Figures 17 and 18), with very small sized microvilli. Their electron-plasm contained a large number of vacuoles in addition to other cell organelles.

The propria-submucosa was comprised of mainly the lymphocytes, a few plasma cells, macrophages, 


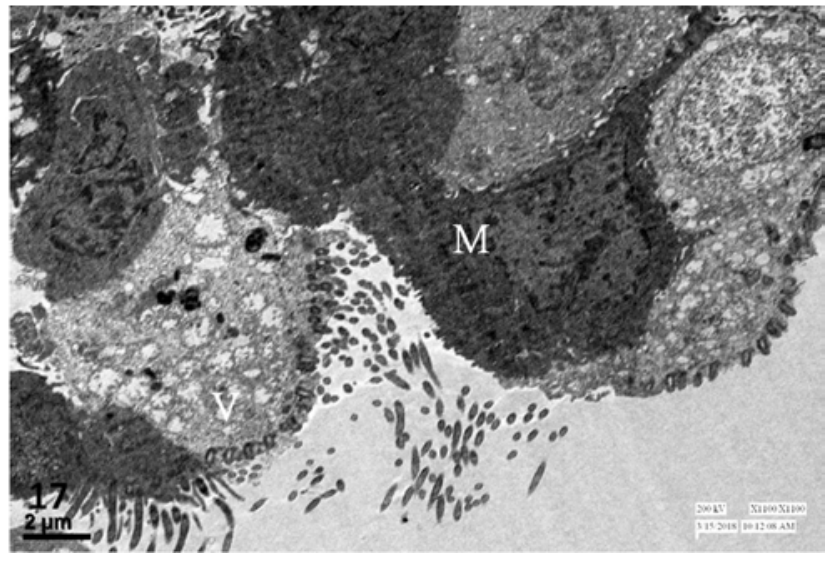

Figure 17: Transmission electron-micrograph of the tubal tonsil showing modification of the respiratory epithelium into follicle-associated epithelium having microvillus (V) and $M-$ cells (M). x 1100; (bar $2 \mu \mathrm{m})$.

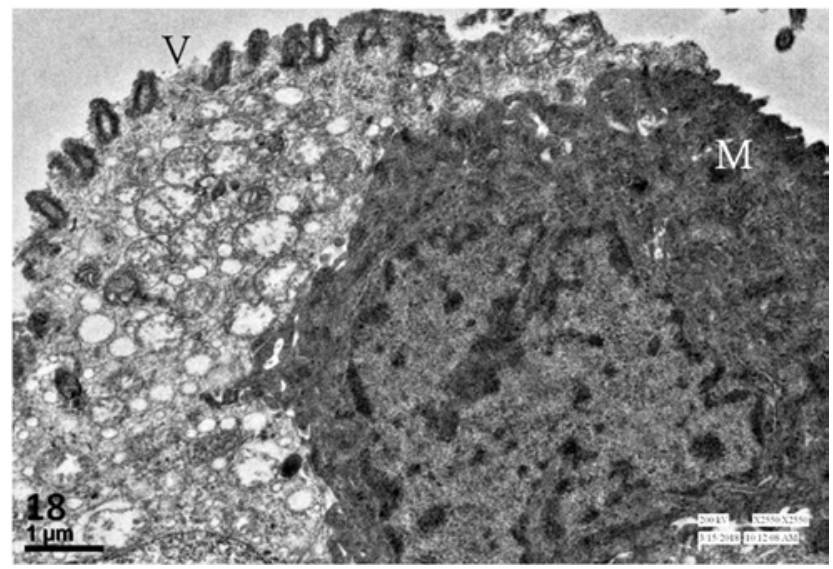

Figure 18: Transmission electron-micrograph of the tubal tonsil showing higher magnification of the microvillus $(\mathrm{V})$ and M-cells (M). x 2550 (bar $1 \mu \mathrm{m}$ ).

interdigitating cells, fine blood capillaries, and a few granulocytes. A few high endothelial venules (HEVs) were also observed which showed the trafficking of

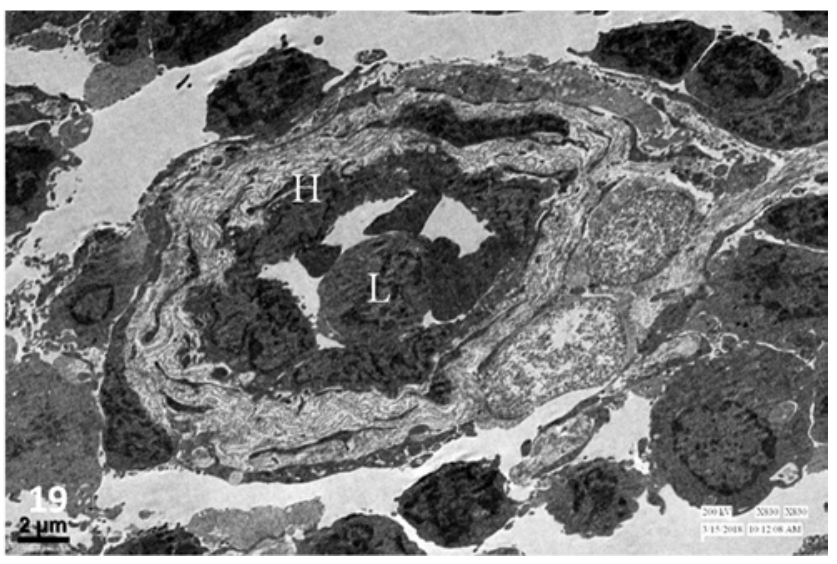

Figure 19: Transmission electron-micrograph of the tubal tonsil showing high endothelial venule $(\mathrm{H})$ with lymphocyte (L). x 830 (bar $2 \mu \mathrm{m})$. lymphocytes either inter-endothelial or transvascular. The HEVs were specialised structures lined by cuboidal to columnar shaped endothelial cells attached by desmosomes (Figure 19). These endothelial cells having electron-dense nuclei possessed cytoplasmic processes of varying shapes and dimensions towards the luminal surface and contained different cell organelles. In addition to the presence of mitochondria, Golgi bodies, endoplasmic reticulum, small-sized vesicles, caveolae, multivesicular bodies and a few filaments were also observed. The small vesicles arranged in small clusters towards free luminal surface were vesiculo-vacuolar organelle (VVOs).

\section{DISCUSSION}

A respiratory type of ciliated epithelium lined the tubal tonsil of the buffaloes as in the horse [10], sheep $[17,18]$, goat [19, 20], pig [11, 21], and the camel [22] The undulating appearance of the epithelium might provide better entrapment and attachment of foreign particles including invading antigens [10]. The epithelium comprising of different cell types presented 8-12 rows of nuclei in contrast to 6-14 in horse [10], 6 10 in sheep and goat $[18,20]$.

The histological features of the pseudostratified columnar ciliated epithelium with goblet cells with respect to cytoplasm, shape of nuclei and distribution of chromatin material resembled with those of the horse [10]. The ciliated epithelial lining aids in drainage of mucus and debris down to the nasopharynx [10]. The goblet cells were strongly positive for neutral and acidic mucopolysaccharides with the predominance of the latter along with glycogen as reported in the sheep [18] and the pig [11]. The PAS activity was lacking at the majority of the portion of the epithelium indicating absence of goblet cells. Alcianophilic positive reaction confirmed the presence of weakly sulfated acidic mucosubstances, hyaluronic acid and sialomucins similar to those of pig [11]. These cells also showed positive reaction for mucin whereas a weak reaction by colloidal iron indicated presence of acidic mucopolysaccharides. The secretions of the goblet cells had more than $4 \%$ content of cysteine as demonstrated by performic acid-Alcian blue.

Lymphocytes infiltration was observed at different heights of the epithelium especially towards the free surface in the region where underlined lymphoid tissue was present. This was structurally designated as lymphoepithelium as described previously in the horse [10], and in the pig [11]. Tonsillar intraepithelial 
lymphocytes (IELs) in the lymphoepithelium along with antigen presenting cells interact with antigens, prime immune responses, and contribute to early host defense or allergic reactions [3]. The lymphoepithelium in the regions of lymphoid follicles modified into follicleassociated epithelium due to absence of the ciliated and goblet cells with an increased number of lymphocytes as described earlier in different species $[10,11,18]$. Thus, the presence and or predominance of lymphoid cells were characteristic of FAE [2]. Lack of goblet cells and mucus may facilitate direct contact of micro-organisms with the FAE including M-cells [10]. The FAE enabled MALT-specific requirements such as proximity between the surface and immune cells, controlled sampling and translocation of antigen to subepithelial lymphoid follicles [3].

The FAE of different types exhibited characteristic features and at few places the infiltration of the lymphoid cells was so much predominant that it was difficult to discern the epithelial cells. A few most superficially placed dome shaped cells were designated as M-cells as reported in the sheep [18] and the pig [11]. The distinctive morphological features of M-cells had earlier been described in nasopharyngeal tonsil of the horse and buffalo by histochemical and ultrastructural techniques [7, 12]. The M-cell apical surface allowed trans-epithelial transport of antigen across epithelial barrier to underlying immune cells where processing and initiation of immune responses occur [23]. Thus, Mcells represented the first cells involved in the initiation of immune response against harmful antigens at the inductive sites of MALT [24].

Similarly, some of the surface epithelial cells were dome shaped but these were not associated with the lymphoid follicles or organised lymphoid aggregations. The nuclei of these cells occupied majority of the portion whereas, a narrow rim of the cytoplasm led to a dome shape appearance. These cells may or may not be associated with the lymphocytes and were considered equivalent to the M-cells as described in the tubal tonsil of the horse [10]. These cells seem equivalent to intestinal villus M-cells discovered in nonfollicle-associated epithelium which acted as distinct gateway for the uptake of gut antigen [25]. M-cells, that were not necessarily in contact with lymphoid cells and lacked a cytoplasmic pocket, were detected using ultrastructural criteria [26] and histochemistry [27, 28]. The morphological variation of M-cells might be attributed to reversible interchange between M-cells and epithelial cells [29], thus resulting in diverse intermediate cell types bearing certain characteristics of both cell types [30].

The propria-submucosa constituted by different types of connective tissue fibres and cells resembled with that of the horse [10], goat [18] and the pigs [11, 20]. A variable amount of lymphoid tissue was irregularly distributed throughout the propriasubmucosa with predominance in the form of linearly arranged 2-3 lymphoid follicles. The number of these follicles (nodules) varied from 41 to 150 in ovine [17]. The follicles were comprised of lymphocytes, plasma cells, macrophages, inter-digitating cells (IDC) and follicular dendritic cells as reported in the horse [10].

The interfollicular areas also contained a few high endothelial venules (HEVs) similar to those of the sheep [18] and pig [11]. In the horse, both CD4+ and CD8+ cells were identified in the FAE, lamina propria mucosae, and parafollicular and interfollicular areas, with the parafollicular areas more heavily populated with CD4+ cells [10]. However, the corona and the germinal centres were lacking in the present study. The elastic fibres were abruptly increased in the form of an irregular interrupted layer toward the deeper part of the propria-submucosa which might be a replacement of the muscle layer. The glandular acini had a predominance of acidic mucopolysaccharides which was in contrary to the distribution in the goblet cells of the epithelium. The reactions for other mucopolysaccharides and cysteine were similar to those observed in epithelial cells during the present study.

The tubal tonsil surface under SEM presented a dense mat of cilia with bleb like free tips as reported in the horse [10], sheep [18] and the pig [11]. At some place, round to oval openings represented openings of glandular ducts. Microvillus cells were categorised into different types depending on the size of microvilli similar to those of the horse [10], sheep [18] and the pig [11]. The FAE regions were represented where the microvillus cells were dominant than the ciliated cells. The least number of microvillus cells with smallest microvilli were considered as the M-cells as previously reported in the horse [10], sheep [18] and the pig [11]. In addition, a few microvillus cells possessing both microvilli and cilia were delineated which were otherwise difficult to identify by light microscopy.

TEM confirmed the observations made under light microscopy and in addition highlighted the details of the nuclei and cell organelles. The ultrastructural features 
of different cell types of respiratory epithelium were similar to those of the horse [10]. The follicleassociated epithelium had different types of microvillus cells (Mv). The large sized $\mathrm{Mv}$ cells were electrondense in nature as described in ovine [31] but were equivalent of type-2 $\mathrm{Mv}$ cells described in the tubal tonsil of the horse [10]. The electron-lucent Mv cells were described as type-2 $\mathrm{Mv}$ cells in ovine [31]. In addition, moderate electron-dense $\mathrm{Mv}$ cells were observed in the present study. These $\mathrm{Mv}$ cells presented the different cell organelles especially the mitochondria, Golgi bodies, smooth and rough endoplasmic reticulum, a few lysosome-like and a few secretory granules-like structures. In the horse, type-I cells resembled $\mathrm{M}$ - cells but with a reduced number of cell organelles and loss of bundles of filaments which was characteristic of maturation of the antigen presenting cells [10]. M-cells equivalent were observed in between these $\mathrm{Mv}$ cells, with very small sized microvilli and their electronplasm contained large number of vacuoles in addition to other cell organelles as reported in the horse [10]. In the horse, small sized vesicles present towards the luminal surface were believed to be involved in uptake and absorption of soluble particles by pinocytosis [10]. Some vesicles in the M-cell apical cytoplasm were reported to contain cathepsin $\mathrm{E}$, an endosomal protease, which generates an acidic milieu [32]. The $M$ cells of the respiratory epithelium were structurally similar to those of the FAE and may be targeted site for the entry of antigens [10].

The propria-submucosa comprised of mainly the lymphocytes, a few plasma cells, macrophages, interdigitating cells, fine blood capillaries, and a few granulocytes. In the horse, the parafollicular and interfollicular areas were populated by interdigitating cells with processes of varying length and thickness intermingled with other cells and cell organelles additional to filaments [10]. A few HEV's were also observed which showed the trafficking of lymphocytes either inter-endothelial or transvascular as reported in human $[33,34]$ and the different domestic species like horse [10], and camel [35]. The HEVs have been reported in T-cell and infrequently along the border of B-cell areas [36]. The receptors on the endothelial cells corresponding to molecules on lymphocytes result in rolling, adhesion activation, and transmigration of lymphocytes [37]. The passage of lymphocytes through transvascular route extends from luminal surface to exit outer basal surface of the endothelial cells [38] whereas lymphocytes attach to endothelial cells by means of short cytoplasmic projections present in interendothelial clefts and migration takes place by diapedesis through inter-endothelial trafficking [33]. The ultrastructural features of these endothelial cells especially their processes, distribution of cell organelles, presence of caveolae and vesiculovacuolar organelle (VVO's) were same as observed in the HEV's of the nasopharyngeal tonsil of buffaloes [12]. The cytoplasmic processes of the endothelial cells increased the surface area and may convert a laminar flow into a turbulent one and thus increased contacts between circulating lymphocytes and the endothelial surface [10]. It has been mentioned that caveolae were involved in endocytosis, transcytosis, signal transduction, mechanotransduction, potocytosis and cholesterol trafficking [39]. The VVO's regulates transvascular cell passage of soluble macromolecules [40]. Their stomata and diaphragms provided a structural basis for regulation of tracer passage across the microvascular endothelium [41]. The larger vesicles and vacuoles of VVOs may be formed by fusion of two or more caveolin positive caveolae-sized unit vesicles similar to those of capillary caveolae [42].

\section{CONCLUSION}

The pseudostratified columnar ciliated epithelium of the tubal tonsil was modified into characteristic lymphoepithelium and the follicle associated epithelium. The presence of different types of mucopolysaccharides in the goblet cells was helpful in demarcation of transitional areas of modifications. The histology, histochemistry and electron-microscopy supported the findings of each other during the present comprehensive study. The presence of lymphoepithelium, patches of FAE having M-cells, lymphoid tissue, macrophages and high endothelial venules showing inter-endothelial and transvascular migration make the tubal tonsil a suitable candidate for immune studies and exploiting it as an alternative site for intranasal vaccination for different bacterial disease including hemorrhagic septicemia in buffaloes. In addition, M-cell like cells observed during present study need to confirm their physiological role in relation to inhaled antigen.

\section{ACKNOWLEDGEMENT}

The Indian Council for Cultural Relation (ICCR, African Scholarship Section) is gratefully acknowledged for the sponsorship of Ph.D. program of Dr. Ibrahim Alhaji Girgiri.

\section{CONFLICT OF INTEREST}

The authors do not have any conflict of interest. 


\section{FUNDING STATEMENT}

The authors did not get any funding for this research work except fellowship to the first author for his Doctoral programme.

\section{REFERENCES}

[1] Bernstein JM, Yamanaka N, Nadal D. Immunobiology of the tonsils and adenoids In: Handbook of mucosal immunology, Ogra PL, Mestecky J, Lamm ME, Strober W, McGhee JR, Bienenstock J. (eds). Academic Press, San Diego 1994. https://doi.org/10.1016/B978-0-12-524730-6.50055-5

[2] Brandtzaeg P. Immunobiology of the tonsils and adenoids. Mucosal Immunol 2015; 2: 1985-2016. https://doi.org/10.1016/B978-0-12-415847-4.00103-8

[3] Chacker A. Anatomy and microanatomy of tonsils. Ency Immunobiol 2015; 3: 420-26.

https://doi.org/10.1016/B978-0-12-374279-7.07005-3

[4] Pabst R. Plasticity and heterogeneity of lymphoid organs. What are the criteria to call a lymphoid organ primary, secondary or tertiary? Immunol Lett 2007; 112: 1-8. https://doi.org/10.1016/j.imlet.2007.06.009

[5] Cesta MF. Normal structure, function and histology of mucosa-associated lymphoid tissue. Toxicol Pathol 2006; 34: 599-608. https://doi.org/10.1080/01926230600865531

[6] Bockman DE, Cooper MD. Pinocytosis by epithelium associated with lymphoid follicles in the bursa of Fabricius, appendix, and Peyer's patches. An electron microscopic study. Am J Anat 1973; 136: 455-78. https://doi.org/10.1002/aja.1001360406

[7] Kumar P, Timoney JF, Sheoran AS. M cells and associated lymphoid tissue of the equine nasopharyngeal tonsil. Equine Vet J 2001; 33: 224-30.

https://doi.org/10.2746/042516401776249697

[8] Neutra MR, Mantis NJ, Kraehenbuhl JP. Collaboration of epithelial cells with organised mucosal lymphoid tissues. Nat Immunol 2001; 2: 1004-09.

https://doi.org/10.1038/ni1101-1004

[9] Perry M, Whyte A. Immunology of the tonsils. Immunol Today 1998; 19: 414-21. https://doi.org/10.1016/S0167-5699(98)01307-3

[10] Kumar P, Timoney JF. Immunohistochemistry and ultrastructure of the equine tubal tonsil. Anat Histol Embryol 2005; 34: 141-48. https://doi.org/10.1111/j.1439-0264.2005.00582.x

[11] Ranjit, Kumar P, Kumar P, Singh G. Histology, histochemistry and scanning electron microscopy of tubal tonsil of the young pigs. Vet Res Int 2015; 3: 1-6.

[12] Girgiri IA, Kumar P. Histology, histochemistry and ultrastructure of the nasopharyngeal tonsil of the buffalo (Bubalus bubalis). Anat Histol Embryol 2019; 48: 375-83. https://doi.org/10.1111/ahe.12452

[13] Girgiri IA, Kumar P. Histological and histochemical studies on the lingual tonsil of the buffalo (Bubalus bubalis). J Buff Sci 2019; 8: 68-76.

https://doi.org/10.6000/1927-520X.2019.08.03.3

[14] Luna LG. Manual of histologic staining methods of Armed Forces Institute of Pathology. 3rd ed. New York: McGraw-Hill Book Company 1968.

[15] Crossman GA. A modification of Mallory's connective tissue stain with a discussion of principles involved. Anat Rec 1937; 69: 33-8. https://doi.org/10.1002/ar.1090690105

[16] Pearse AGE. Histochemistry: theoretical and applied. 3rd ed. London: Churchill Livingstone 1968.
[17]

Cocquyt G, Baten T, Simoens P, Van den Broeck W. Anatomical localisation and histology of ovine tonsils. Vet Immunol Immunopathol 2005; 107: 79-86. https://doi.org/10.1016/j.vetimm.2005.03.012

[18] Kumar P, Kumar P. Histology, histochemistry and scanning electron microscopic studies on the tubal tonsil of the sheep. Indian J Anim Sci 2012; 82: 61-63.

[19] Casteleyn C, Breugelmans S, Simoens P, Van den Broeck $\mathrm{W}$. The tonsil revisited: Review of the anatomical localisation and histological characteristics of the tonsils of domestic and laboratory animals. Clin Dev Immunol 2011. https://doi.org/10.1155/2011/472460

[20] Indu VR, Lucy KM, Chungath JJ, Ashok N, Maya S. Histology and scanning electron microscopy of the tubal tonsil of goats. Vet World 2015; 8: 1011-14. https://doi.org/10.14202/vetworld.2015.1011-1014

[21] Liu Z, Yu Q, Li P, Yang Q. Histological and ultrastructura examinations of porcine tonsils. Anat Rec 2012; 295: 686-90. https://doi.org/10.1002/ar.21534

[22] Yang C, Yuan G, Xu Z, Shoa B, Wang J. The topography and the microscopic structure of tonsils in the adult Bactrian camel (Camelus bactrianus). J Camel Pract Res 2011; 18(2): 155-63.

[23] Corr SC, Cormac CGM, Gahan Colin H. M-cells: origin, morphology and role in mucosal immunity and microbial pathogenesis. FEMS Immunol Med Microbiol 2008; 52: 2-12. https://doi.org/10.1111/j.1574-695X.2007.00359.x

[24] Hathaway LJ, Kraehenbuhl JP. The role of M-cells in mucosal immunity. Cell Mol Life Sci 2000; 57: 323-32. https://doi.org/10.1007/PL00000693

[25] Jang $\mathrm{MH}$, Kweon MN, Iwatani K, Ya,mamoto M, Terahara, K, Sasakawa C, Suzuki T, Nochi Tyokota Y, Rennert PD, Hiroi $\mathrm{T}$, Tamagawa $\mathrm{H}$, lijima $\mathrm{H}$, Kunisawa J, Yuki $\mathrm{Y}$, Kiyono $\mathrm{H}$. Intestinal villous $M$ cells: an antigen entry site in the mucosal epithelium. Proc Natl Acad Sci 2004; 101: 6110-15. https://doi.org/10.1073/pnas.0400969101

[26] Bye WA, Allan $\mathrm{CH}$, Trier JS. Structure, distribution, and origin of $\mathrm{M}$ cells in Peyer's patches of mouse ileum. Gastroenterol 1984; 86: 789-801.

[27] Pappo J. Generation and characterisation of monoclonal antibodies recognising follicle epithelial $\mathrm{M}$ cells in rabbit gutassociated lymphoid tissues. Cell Immunol 1989; 120: 31-41. https://doi.org/10.1016/0008-8749(89)90172-X

[28] Gebert A, Hach G, Bartels H. Co-localization of vimentin and cytokeratins in M-cells of rabbit gut-associated lymphoid tissue (GALT). Cell Tissue Res 1992; 269: 331-40. https://doi.org/10.1007/BF00319625

[29] Knoop KA, Kumar N, Butler BR, Sakthivel SK, Taylor RT, Nochi T, Akiba $\mathrm{H}$, Yagita $\mathrm{H}$, Kiyono $\mathrm{H}$, Williams I. RANKL is necessary and sufficient to initiate development of antigensampling M cells in the intestinal epithelium. J Immunol 2009; 183: $5738-47$

https://doi.org/10.4049/jimmunol.0901563

[30] Savidge TC. The life and times of an intestinal M cell. Trends Microbiol 1996; 4: 301-6. https://doi.org/10.1016/0966-842X(96)10052-4

[31] Casteleyn C, Cornelissen M, Simoens P, Van den Broeck W. Ultramicroscopic examination of the ovine tonsillar epithelia. Anat Rec 2010; 293: 879-89. https://doi.org/10.1002/ar.21098

[32] Allan $\mathrm{CH}$, Mendrick DL, Trier JS. Rat intestinal M cells contain acidic endosomal-lysosomal compartments and express class II major histocompatibility complex determinants. Gastroenterol 1993; 104: 698-708. https://doi.org/10.1016/0016-5085(93)91004-2

[33] Indrasingh I, Chandi G, Vettivel S. Route of lymphocyte migration through the high endothelial venule (HEV) in human palatine tonsil. Annals Anat 2002; 184: 77-84. https://doi.org/10.1016/S0940-9602(02)80040-1 
[34] Hafeez A, Khan MY, Minhas LA. The relative distribution of high endothelial venules in the subepithelial lymphoid compartments of human palatine tonsil. Annals Pak Inst Med Sci 2008; 4: 223-26.

[35] Zidan M, Pabst R. The microanatomy of the palatine tonsils of the one-humped camel (Camelus dromedarius). Anat Rec 2009; 292: 1129-97. https://doi.org/10.1002/ar.20948

[36] Hayashi S, Kikuta A, Ohtsuka A, Masuda Y. Microvascular architecture of rat nasal associated lymphoid tissue. Arch Histol Cytol 1991; 5: 279-87. https://doi.org/10.1679/aohc.54.279

[37] Zidan M, Jecker P, Pabst R. Differences in lymphocyte subsets in the wall of high endothelial venules and the lymphatics of human palatine tonsils. Scand J Immunol 2000; 51: $372-76$ https://doi.org/10.1046/j.1365-3083.2000.00681.x

[38] Marchesi VT, Gowans JL. The migration of lymphocyte through the endothelium of venules in lymph nodes: an electron microscopic study. Proc R Soc Lond 1964; 159: 283-90.

https://doi.org/10.1098/rspb.1964.0002
[39] Stan RV. Structure and function of endothelial caveolae. Microsc Res Tech 2002; 57: 350-64. https://doi.org/10.1002/jemt.10089

[40] Feng D, Nagy JA, Dvorak HF, Dvorak AM. Ultrastructural studies define soluble macromolecular, particulate, and cellular transendothelial cell pathways in venules, lymphatic vessels, and tumor-associated microvessels in man and animals. Micros Res Tech 2002; 57: 289-326. https://doi.org/10.1002/jemt.10087

[41] Dvorak AM, Feng D. The vesiculo-vacuolar organelle (VVO): a new endothelial cell permeability organelle. J Histochem Cytochem 2001; 49: 419-31. https://doi.org/10.1177/002215540104900401

[42] Vasile E, Qu-Hong H, Dvorak F, Dvorak AM. Caveolae and vesiculo-vacuolar organelles in bovine capillary endothelial cells cultured with VPF/VEGF on floating matrigel collagen gels. J Histochem Cytochem 1999; 47: 159-67. https://doi.org/10.1177/002215549904700205

DOI: https://doi.org/10.6000/1927-520X.2020.09.08

(C) 2020 Girgiri and Kumar; Licensee Lifescience Global.

This is an open access article licensed under the terms of the Creative Commons Attribution Non-Commercial License (http://creativecommons.org/licenses/by-nc/3.0/) which permits unrestricted, non-commercial use, distribution and reproduction in any medium, provided the work is properly cited. 